ARTÍCULO OPINIÓN

\title{
La biblioteca médica personal ¿Es actualmente necesaria?
}

\author{
The personal medical library. Is it currently necessary?
}

Carlos Alberto Javier Zepeda

Médico Especialista en Patología y Microbiología, Centro de Patología Clínica, Tegucigalpa.

Una biblioteca personal es el mapa de la construcción del pensamiento y la trayectoria intelectual de su propietario.

Anónimo

Históricamente los libros han sido compañeros del médico desde que comienza los primeros estudios en la Universidad. Los seres humanos son criaturas de hábitos: los médicos deben adquirir este tipo de hábito opcional de leer en su período formativo, es decir en la Escuela de Medicina y desarrollarlo plenamente mediante una práctica repetitiva en un horario cuando pueden ser observados (Ver Figura 1). Solía ser una costumbre la adquisición de obras de texto para el estudio de las asignaturas desde los primeros años, así, los libros de Anatomía, Histología, Embriología y otras materias básicas, iban quedando en los estantes a medida que se obtenían las obras de las clases intermedias y clínicas y de esta manera se convertían en el primordio de lo que sería a futuro una pequeña colección de referencia. Esa costumbre ha ido disminuyendo en las últimas décadas a medida que la lectura en los libros "gordos", es una exigencia cada vez menor por parte de los docentes y a la disposición de otras formas de obtener la información en forma de conceptos resumidos, lectura digital y libros en línea, que son aprovechadas por el estudiante cada vez más ocupado.

No siempre era posible, y creo que ahora tampoco lo es, adquirir los textos; su costo relativamente elevado, la escasez de librerías médicas y otras razones, era un impedimento para algunos estudiantes, que se veían en la necesidad de obtener libros por préstamo de otros compañeros o usar lo que hubiese disponibles en la biblioteca de la Escuela de Medicina. Esta realidad local es menos obvia en otros países. Muchas veces, los libros usados eran vendidos a la siguiente generación, a manera de obtener fondos para la compra del material bibliográfico del año siguiente. El esfuerzo de la Organización Panamericana de la Salud para mantener un programa de dotación de textos (PALTEX) eventualmente fue terminado.

Recibido: 19-12-2019; Aceptado para publicación 14-02-2020

Dirección para correspondencia: Dr. Carlos A. Javier Zepeda

Correo electrónico: cajavierz@yahoo.com

Declaración de relaciones y actividades financieras y no financieras y conflictos de interés: ninguna.

DOI: https://doi.org/10.5377/rmh.v88iSupl.1.11680

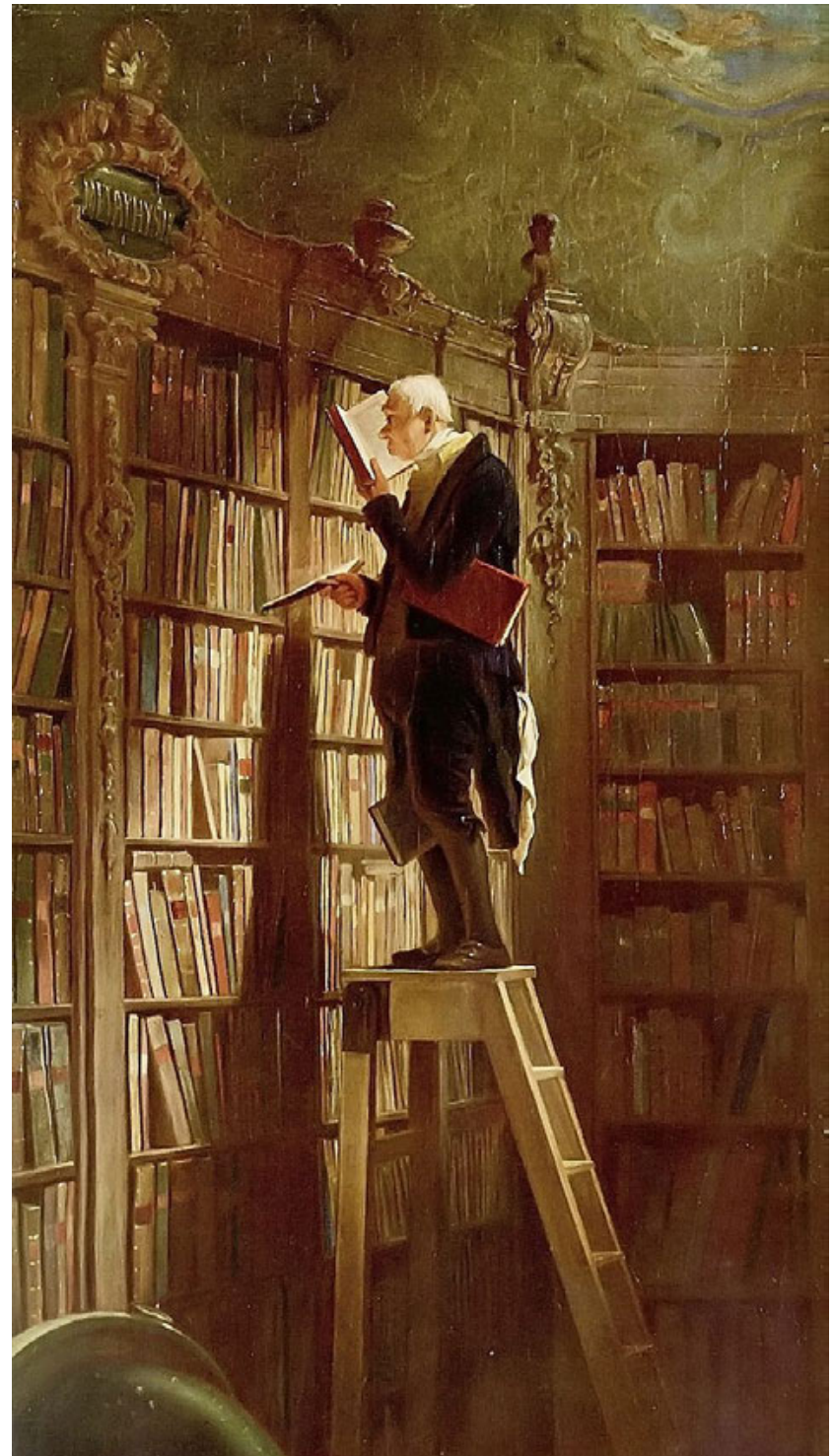

Figura 1. Pintura del artista alemán Carl Spitzweg, impresionista destacado, titulada Der Bücherwurm ("El ratón de biblioteca"), aproximadamente 1850 (Fuente https://es.wikipedia.org/wiki/El rat\%C3\%B3n de biblioteca).

De alguna forma, algunos de los textos de estudio iban quedando en lo que era la biblioteca del estudiante y la colección se iba aumentando poco a poco con la aportación de 
nuevas ediciones, monografías, libros especializados y hasta colecciones de revistas médicas, hasta formar una verdadera biblioteca personal, cuya función, aparte de engalanar la oficina o el espacio de estudio en el hogar, era tener a la mano fuentes de consulta para resolver dudas o indagar temas, sin necesidad de tener que viajar hasta los depósitos más formales en las bibliotecas de la Universidad, lo cual requería dedicación de tiempo aparte y verdadero interés. Esto constituía un quehacer normal para aquellos médicos con una orientación académica como parte de su ocupación, ya que en general, para otros, las actividades del trabajo diario todavía suelen ser un impedimento para que el médico se aproxime más a la lectura.

Es así como se ha descrito que "...Las universidades generalmente son consideradas como ciudadelas de aprendizaje y centros de excelencia. Estas tienen recursos, tanto humanos como materiales, necesarios para la producción de mano de obra, trabajo diestro y facilidades para la investigación, la enseñanza, el aprendizaje y el desarrollo comunitario. Para alcanzar esto, se crean las bibliotecas con el objeto de brindar el apoyo necesario y la dirección para ayudar a sus instituciones paternas a alcanzar su visión y misión, adquiriendo, organizando, preservando y diseminando información a los usuarios. Se espera, por tanto, que construyan colecciones de buena calidad que comprendan recursos informativos en todas sus ramificaciones. La colección debe apoyar y sustentar todos los programas académicos que ofrece la Universidad, así como las necesidades de investigación, enseñanza y aprendizaje". ${ }^{1}$ También se ha definido que "...La biblioteca es el nervio o epicentro donde tanto estudiantes como profesores acuden para su nutrición académica". ${ }^{2}$

Para muchos médicos la devoción por la lectura y la posesión de libros los convierte en bibliotecarios personales, algunos verdaderos bibliófilos, otros dedicados bibliómanos y unos pocos hasta consumados "bibliófagos". La biblioteca del médico es un reflejo de sus intereses personales, por lo que fuera del contexto general, no existen dos iguales. Cada colección es única y valiosa. Como lo ha dicho Alonso Cueto, "nuestros libros, son nuestra biografía clandestina...no expresan lo que vivimos, sino lo que hubiéramos querido vivir...nuestra biblioteca es nuestra memoria secreta, el espejo de nuestras obsesiones y traumas...Cada uno creo, construye su biblioteca en relación con uno mismo". ${ }^{3}$

Las colecciones de libros y revistas también se acompañan de otros temas de lectura como son los libros de historia, literatura, política y otras humanidades, que son afines al médico, como ríos que desembocan en el gran mar del pensamiento médico. Aunque la creación de bibliotecas data de tiempos antiguos, el inicio de las bibliotecas privadas se vuelve más común con la invención de la imprenta y la impresión de libros a un costo más accesible. Al igual que los libros religiosos, tomó auge la impresión de libros médicos, desde entonces se ha escrito sobre las bibliotecas médicas personales y sobre la dedicación de algunos personajes de la historia de la Medicina a los libros. Muchas bibliotecas personales cambiaron de dueño o fueron donadas a instituciones académicas y hospitales, algunas obras pasaron a manos de coleccionistas y traficantes de libros raros al morir sus dueños originales.

La importancia de la biblioteca personal ha sido enfatizada como una forma accesible a la educación médica continua. Harold Jehgers (1904-1990), eminente educador médico en los Estados Unidos, consideraba que leer regularmente, con un propósito definido para resolver problemas, es el sello o marca oficial del médico progresista y decía que las ideas de la literatura, adquiridas cuando más se necesitan para resolver una situación clínica, serían recordadas más fácilmente que la información recibida en un aula. Ya que no se contaba en ese entonces con un acceso fácil a una biblioteca médica institucional, recomendaba la creación de una biblioteca personal de consulta, ${ }^{4}$ aunque advertía que una biblioteca personal no debería ser substituto de una biblioteca médica bien establecida. Actualmente es posible resolver este problema si se tiene acceso a internet, sabiendo localizar la información apropiada. Jeghers extendía su recomendación a mencionar cuales deberían ser las características de una biblioteca personal, que incluiría textos, monografías, revistas y material misceláneo, éste último formado por recortes, notas, impresiones, resúmenes personales, panfletos, informes de casos, etc., que representaban un registro de las experiencias educacionales del médico.

Más recientemente Whatley, ${ }^{5}$ ha considerado que organizar una biblioteca personal es un reto difícil ya que, a diferencia de las bibliotecas profesionales y académicas, generalmente no se encuentra con un bibliotecario o catalogador de la colección, aunque hay fuentes de ayuda en internet en este sentido, con la limitación de que algunos de estos sitios solo son para catalogar libros. Con el desarrollo de la información electrónica diseminada a través de internet en los últimos 50 años, el tema de la difusión de conocimientos en salud es controversial, ${ }^{6,7}$ no solo comparando la información impresa y electrónica, sino la confiabilidad de lo que es accesible por la red. Es indiscutible la ventaja que brinda la computación para obtener información y hay quienes han sepultado el interés por los libros. Otros siguen aferrados a la tradición. Creo que debe haber un balance y hoy día una biblioteca personal debe tener acceso a fuentes confiables de consulta en internet y mantener a la mano las obras y fuentes de información en libros, monografías y revistas actualizados en sus campos de interés. Desde luego, decir actualizados significa reponer los textos obsoletos y adquirir periódicamente nuevas fuentes de información. Existen sitios y guías muy serios para consultar la bibliografía médica en internet.

Poseer una biblioteca personal tiene un componente afectivo, la posesión de libros no es lo mismo que la pertenencia de cosas materiales, aun cuando sean para uso personal. Los libros tienen una potencia de vida, fueron escritos por personas que hicieron un esfuerzo mental y físico en su elaboración, quizás también depositaron en su obra su sensibilidad y apego al tema tratado. Tener una colección personal es guardar el pasado para usarlo en el presente y en el futuro, no siempre se alcanza a leer toda la biblioteca personal, pero es un sentimiento agradable saber que alguien más podrá, más adelante, aprovecharla. De manera que poseer los libros de la colección 
personal no solo nos permite tener a la disposición su contenido, sino sentir su compañía, que nos brinda seguridad. Volver a leer un tema o consultar un pasaje en el mismo libro, después de algún tiempo, es como encontrar de nuevo a un amigo que no veíamos hace mucho. Esto es bibliofilia y adquirir nuevos libros es como aumentar los miembros de la familia. Los libros son más que objetos, son nuestra memoria y parte de nosotros mismos.

Moderación y buen criterio son necesarios para la formación de una biblioteca personal, en primer lugar, no se puede disponer de tantos fondos para una colección que no va a ser leída, algunos critican esta actitud llamándola anti-biblioteca, ya que se espera que los libros de una biblioteca sean para ser usados. En japonés la palabra tsundoku significa un conjunto de libros que se han comprado pero que no se han leído todavía. Muchas bibliotecas personales tienen un tsundoku. En la creación de una biblioteca médica personal, si se es partidario de su necesidad, se deben seleccionar los temas de interés del propietario y tener los libros básicos de consulta, las monografías adecuadas, los diccionarios más útiles, etc. No es difícil al inicio construir una guía o temario, que podrá ser modificado a medida que crezca la colección. El idioma es importante, naturalmente se debe acceder a la lectura en el idioma que más se domina, pero no siempre se encuentran las obras deseadas en ese idioma. Preferentemente el libro debe leerse en el idioma que fue escrito originalmente o buscar las traducciones más apropiadas, si las hay.

Como la biblioteca médica personal es un proyecto absolutamente individual, su contenido interesa a muy pocas personas aparte del dueño, hay quien ha escrito que dichas colecciones son un lastre del que es necesario desprenderse antes de morir. Si esa es una decisión, también hay que saber cómo hacerlo. $\mathrm{Ni}$ siquiera su venta es una empresa fácil, tratar de regalarlos dependerá de los intereses de la persona que los va a recibir, las instituciones generalmente los rechazan porque no conocen 0 no valoran su contenido o no tienen espacio para almacenarlos, aparte de que en general se tiene el criterio de que obras de más de cinco años de haber sido publicadas son obsoletas (cuántas biblias habría que tirar al cesto), hay que considerar si hijos 0 nietos con interés en la Medicina podrían ser beneficiarios 0 se puede depositar en carácter de préstamo en alguna organización que los pueda cuidar. El Dr. Manuel Ramiro Hernández (México), se refiere en forma amena a este tema. ${ }^{8}$ Con bastante pena he visto los despojos de lo que fueran algunas bibliotecas personales de médicos hondureños, incluyendo ejemplares de la Revista Médica Hondureña desde sus primeros números. Algunos de los aspectos aquí presentados pueden ampliarse en lecturas adicionales sugeridas. ${ }^{9-11}$

Haciendo un análisis de la realidad, podemos concluir que cada día serán menos las bibliotecas médicas personales, las que se conserven estarán en manos de médicos con mucha afinidad por la lectura o tendencia académica. Dichas bibliotecas estarán conformadas alrededor de temas especializados y como es natural serán dedicadas al servicio del propietario. Se vuelve casi innecesario la protección de colecciones que ocupan más espacio que la utilidad que brindan. Se preservarán las obras que mantengan información técnica de interés, algunos libros clásicos y monografías especializadas, así como los textos de Anatomía. Tendrán más vigencia los libros de historia y biografía médicas, que no suelen pasar de moda. Los temas muy cambiantes como la farmacoterapia, el diagnóstico de laboratorio, los conceptos modernos de biología molecular y otras tecnologías, será muy difícil de mantener actualizados en una biblioteca privada. El médico dependerá cada día más de la información digital teniendo el cuidado de seleccionar bien la confiabilidad de las fuentes de información. No se puede decir que la biblioteca médica personal vaya a desaparecer, pero si es necesario adaptarse a los nuevos métodos de consultar la información y cambiar la dinámica para tener el provecho que deseamos.

\section{REFERENCIAS}

1. Ogom OJ, Etungre IF, Simon BR. Evaluation of medical library collection in the University of Calabar library, Calabar, Nigeria. AASCIT J Educ [internet]. 2015[acceso diciembre 2019];1(3):5257. Disponible en: https://pdfs.semanticscholar.org/4713/2d1df7d 3475dea1463faa226d366e567827a.pdf

2. Yusuf F, Iwu-James J. Use of academic library: a case study of Covenant University, Nigeria. Chinese Librarianship: an International Electronic Journal. 2010[acceso diciembre 2019]30:1-12. Disponible en: http://eprints.covenantuniversity.edu.ng/3277/1/Use $\% 20$ of $\% 20$ Academic $\% 20$ Library.pdf

3. Cueto A. Una biblioteca personal. Letras libres [internet]. 2012. [acceso diciembre 2019]. Disponible en: https://www.letraslibres. com/mexico-espana/una-biblioteca-personal

4. Jeghers HJ. Care, education and research: philosophy and techniques of self-education of the medical student and physician. $\mathrm{N}$ Engl J Med. 1964; 271:1297-1301.

5. Whatley K. Organizing a personal library. Information technology at New York University, Spring-Summer 2008.

6. Lewis Dolan P. $86 \%$ of physicians use Internet to access health information. Am Med News [internet]. 2010[acceso diciembre 2019]. Disponible en http://www.amednews.com/article/20100104/busi$\underline{\text { ness/301049966/7I }}$
7. Kopp J. As medical misinformation infects the internet, doctors seek a cure[internet]. Philly Voice, 2019. [acceso diciembre 2019]. Disponible en https://www.phillyvoice.com/medical-misinformation-internet-doctors-fake-news-social-media-clinicians-physicians-offit-chiang-wakefield/

8. Hernández MR. Las bibliotecas privadas o particulares. El Semanario Sin Limites [internet]. 2018[acceso diciembre 2019]. Disponible en https://elsemanario.com/vida-y-cultura/las-bibliotecasprivadas-0-particulares/

9. Jehgers HJ. Building a personal medical library. An effective technique of self-education for medical students and physicians. Bradford VTS;1982.

10. Fletcher RH, Fletcher SW. Evidence-based approach to the medical literature. J Gen Int Med[internet]. 1997[acceso diciembre 2019];12 (2): 5-14. Disponible en:https://onlinelibrary.wiley.com/ doi/full/10.1046/j.1525-1497.12.s2.1.x

11. Giraldi W. Object lesson: Why we need physical books. The New Republic [internet].2015[acceso diciembre 2019]. Disponible en: newrepublic.com/article/121560/bibliophiles-defense-physicalbooks 